\title{
Análisis de Consecuencias y Actuaciones de Protección Civil en el Terremoto de Lorca (Murcia): Pre-Emergencia, Emergencia y Post-Emergencia
}

\author{
GREGORIO PASCUAL SANTAMARIA ${ }^{1}$, SOFÍA GONZÁlEZ LÓPEZ ${ }^{2}$ \& LUCRECIA \\ AlguACIL AlgUACIL ${ }^{1}$ \\ ${ }^{1}$ Dirección General de Protección Civil y Emergencias \\ ${ }^{2}$ Delegación de Gobierno de Murcia \\ gpascual@procivil.mir.es
}

Recibido: $11 / 05 / 2012$

Aceptado: 30/09/2012

\section{Resumen}

En este artículo se pretende dar una visión resumida de las acciones desarrolladas desde Protección Civil, mediante las que se intentó minimizar los daños a las personas y los bienes, tras los terremotos que ocurrieron en Lorca en mayo del 2011. Con este fin se aplicaron las medidas que dimanan de las funciones de Protección Civil (Previsión, Prevención, Planificación, Intervención y Normalización), definidas en la legislación básica: la Ley 2/1985, del 21 de enero, sobre Protección Civil y el Real Decreto 407/1992, de 24 de abril, por el que se aprueba la Norma Básica de Protección Civil.

En concreto, en esta ocasión se aplicaron: El Plan Estatal de Protección Civil ante el Riesgo Sísmico y el Plan Especial de Protección Civil ante el Riesgo Sísmico de la Región de Murcia (SISMIMUR). De acuerdo a estos planes se realizaron dos convocatorias del Comité Estatal de Coordinación (11 y 12 de mayo). El Comité de Coordinación Operativa Integrado (CECOPI) se convocó el 11 de mayo y se disolvió el 28 de diciembre. Una vez terminadas las acciones necesarias para minimizar los daños y aportar medios y recursos a la emergencia.

En resumen el terremoto produjo 9 fallecidos, 324 heridos (3 graves, 49 requirieron hospitalización, el 23 de mayo aún quedaban hospitalizadas 6 personas), miles de albergados en 4 campamentos provisionales uno de los cuales se mantuvo hasta el 30 de octubre. En el texto, se resume la estadística de edificios dañados y los medios que actuaron en la emergencia.

En el momento actual y en aplicación del "Real Decreto ley 6/2011 del 13 de mayo por el que se adoptan medidas urgente para reparar los daños causados por los movimientos sísmico acaecidos el 11 de mayo de 2011 en Lorca, Murcia", se han analizado 13.028 solicitudes y se han liberado 382,3 millones de euros por parte del Consorcio de Compensación de Seguros después de analizar más de 31.00 expedientes, 10 meses después de los acontecimientos el Estado ha liberado 19.093.760,78€.

Palabras clave: Terremoto, Lorca, Daños, Protección Civil.

\section{Analysis of consequences and Civil Protection activities in the Lorca earth- quake (Murcia): Pre-emergency, Emergency and Post emergency}

\section{Abstract}

This article aims to provide a summary of the actions taken by Civil Protection Organizations, after the earthquakes that occurred in Lorca, May 2011, in order to minimize damage to people and property. With this aim, measures that arise from the functions of Civil Protection were applied (Anticipation, 
Prevention, Planning, Intervention and Normalization) as defined in the basic legislation: Civil Protection Act 2/1985 of January 21 and Royal Decree 407/1992 of 24 April, approving the Basic Rule of Civil Protection.

Specifically, two plans were applied this time: The State Civil Protection Plan to the Seismic Risk and the Civil Protection Special Plan to the Seismic Risk - Region of Murcia (SISMIMUR). According to these plans two meetings of the State Coordinating Committee were called on May 11 and 12 . The Integrated Operational Coordinating Committee (CECOPI) was convened on May 11 and dissolved on December 28, once the necessary actions to minimize damage and to provide means and resources to the emergency were completed.

In summary, the earthquake caused 9 deaths, 324 injuries ( 3 serious, 49 required hospitalization, on May 23 six people were still hospitalized), thousands of people were housed in 4 temporary camps, one of which was maintained until the 30 October. The text summarizes the statistics of damaged buildings and the means that intervened in the emergency response.

At present and in application of the "Royal Decree Law 6/2011 of 13 May by adopting urgent measures to repair damage caused by seismic movements that occurred on May 11, 2011 in Lorca, Murcia", 13.028 applications have been analyzed and 382,3 million euro's have been released by the Insurance Compensation Consortium after analyzing more than 31.000 files, besides 10 months after the events the State has released 19.093.760,78€.

Keywords: Earthquake, Lorca, Damage, Civil Protection.

\section{Referencia normalizada}

Pascual Santamaría, G. , González, S. \& Alguacil Alguacil, L. (2012). Análisis de consecuencias y actuaciones de Protección Civil en el terremoto de Lorca (Murcia): Pre-Emergencia, Emergencia y Post-Emergencia . Física de la Tierra, 24, 343-362.

Sumario: Introducción. 1. Previsión. 2. Prevención. 3. Planificación. 3.1. Plan Estatal de Protección Civil ante el Riesgo Sísmico 3.2 Plan de Protección Civil ante el Riesgo Sísmico de la Comunidad Autónoma de Murcia (SISMIMUR).3.3. Sistemas de información sísmica 4. Intervención 4.1. Primer Terremoto. 4.2. Segundo Terremoto 5. Normalización. 6. Conclusiones. Referencias bibliográficas.

\section{Previsión}

Así como para otros riesgos naturales: meteorológicos, hidrológicos incluso volcánico, la función de previsión es indispensable para la generación de mensajes preventivos y actuaciones preparatorias, para el fenómeno sísmico, el desarrollo actual de la ciencia no permite que se realicen predicciones, entendiéndose estas como el conocimiento del lugar, la hora y el tamaño de los terremotos que puedan ocurrir.

Para que una previsión sísmica sea realmente efectiva, los terremotos deberían predecirse de tal forma que los errores de las variables que los describan (magnitud o intensidad, localización espacial y temporal) sean útiles para la actuación y el desarrollo de recomendaciones a corto plazo por parte de los servicios de Protección Civil. Esto no es posible en el momento actual, sin embargo la ciencia nos proporciona información en dos ámbitos:

- Análisis estadísticos de la probabilidad de ocurrencia de terremotos, básicos para el conocimiento de la peligrosidad sísmica. Estos análisis están recogidos en la Norma de Construcción Sismorresistente que obliga a determinadas formas de 
construir en función de las zonas con mayor probabilidad de ocurrencia de terremotos destructores.

- Avisos de terremotos ya ocurridos. Estos informes con el avance de las nuevas tecnologías y los nuevos medios de transmisión de la información, cada vez se ponen a disposición de Protección Civil en menos tiempo, y con una mayor precisión tanto en la localización espacial como temporal. Además estos avisos se realizan para terremotos cada vez de menor magnitud.

Todas estas informaciones permiten actuar con mayor seguridad en los ámbitos de la prevención, planificación e intervención que desarrollamos a continuación.

\section{Prevención}

La función de prevención en el ámbito del riesgo sísmico está contemplada en la legislación española mediante la Norma de Construcción Sismorresistente del año 2002 (NCSR-02) y la Norma de Construcción Sismorresistente para Puentes del año 2007 (NCSP-07). En estas normas se establecen las probabilidades de ocurrencia en las diferentes zonas del territorio español de terremotos de características destructoras y además dictan las medidas para que aquellos edificios que se construyan a partir de la publicación de las mismas, tengan mayores garantías de causar los menores daños posibles. Las diferentes normas de construcción sismorresistentes suponen una premisa para minimizar los daños.
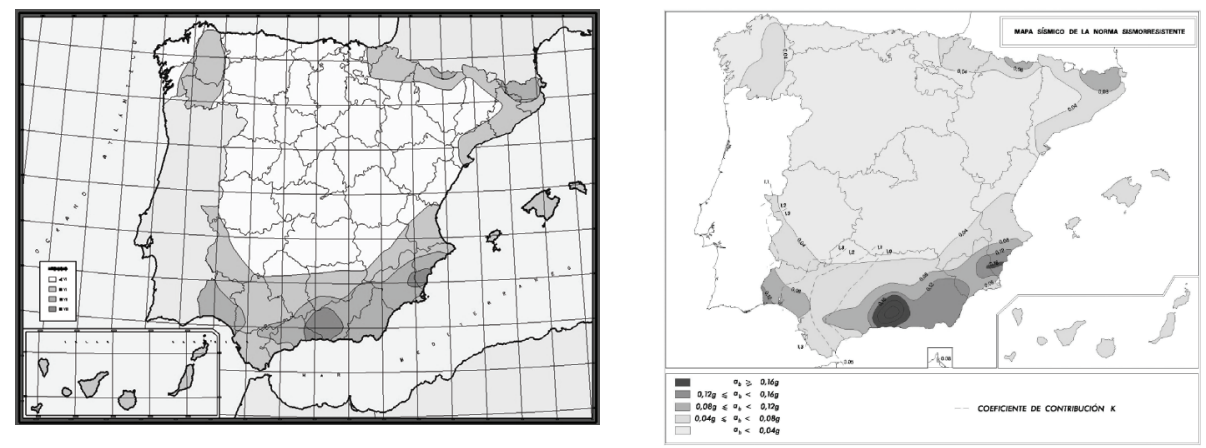

Fig. 1. Mapas de peligrosidad sísmica publicados en la Directriz Básica de Protección Civil ante el Riesgo Sísmico y en la Norma de Construcción Sismorresistente - 02.

\section{Planificación}

La Ley sobre Protección Civil (Ley 2/1985 de 2 de enero), en su preámbulo define como una función básica, la planificación de las líneas de actuación para hacer frente a las situaciones de grave riesgo, catástrofe o calamidad pública que pudieran presentarse. 
La Directriz Básica de Planificación de Protección Civil ante el Riesgo Símico, que fue aprobada mediante la resolución del 5 de mayo de 1995, de la Secretaría de Estado de Interior, estableció, que el mapa de probabilidad de ocurrencia editado para la Norma de Construcción Sismorresistente se tomara como base para definir las reglas para que las Comunidades Autónomas afectadas por este fenómeno, elaboren los correspondientes Planes Especiales de Protección ante el Riesgo Sísmico.

Con este fin se han desarrollado los Planes Estatal y de Comunidad Autónoma que se describen a continuación

En la actualidad están homologados por la Comisión Nacional de Protección Civil todos los planes de protección civil de Comunidad Autónoma, ante el riesgo sísmico.

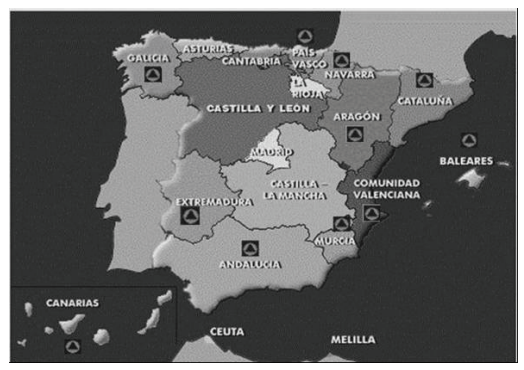

Fig. 2. Comunidades Autónomas que han homologado su Plan de Protección Civil ante el Riesgo Sísmico.

\subsection{Plan Estatal de Protección Civil ante el Riesgo Sísmico}

El Plan Estatal de Protección Civil ante el Riesgo Sísmico establece la organización y procedimientos de actuación de aquellos recursos y servicios del Estado que son necesarios para asegurar una respuesta eficaz del conjunto de las Administraciones Públicas, ante situaciones de emergencia por terremoto en las que esté presente el interés nacional, así como los mecanismos de apoyo a los Planes de Comunidad Autónoma en el supuesto de que éstos lo requieran o no dispongan de capacidad suficiente de respuesta, como ha sido el caso del terremoto de Lorca.

Se elaboró en coordinación con todos los organismos que forman el Comité Estatal de Coordinación según establece la Directriz Básica de Planificación de Protección Civil ante el Riesgo. El Plan fue homologado por la Comisión Nacional de Protección Civil el 3 de diciembre de 2009, aprobado por el Consejo de Ministros y publicándo en el BOE el 9 de abril de 2010.

\subsection{Plan de Protección Civil ante el Riesgo Sísmico de la Comunidad Autóno- ma de Murcia (SISMIMUR)}

El Plan SISMIMUR tiene como objetivos: $1^{\circ}$ establecer la organización y los procedimientos de actuación de los recursos y servicios cuya titularidad corresponde a 
la Comunidad Autónoma de la Región de Murcia y los que puedan ser asignados al mismo por otras Administraciones Públicas, $2^{\circ}$ conocer la peligrosidad existente en la Región de Murcia frente a este riesgo, $3^{\circ}$ estimar la vulnerabilidad de las construcciones cuya destrucción pueda ocasionar víctimas, interrumpir un servicio imprescindible o aumentar los daños por efectos catastróficos asociados, con el al objeto de hacer frente a las emergencias por terremotos ocurridos, o bien, caso de que el episodio catastrófico ocurra en otra Comunidad Autónoma marcar las directrices para que dentro del Plan Estatal, se pueda prestar el concurso necesario a la Comunidad Autónoma afectada.

El Plan Especial de Protección Civil ante el Riesgo Sísmico en la Región de Murcia, fue redactado por la Comunidad Autónoma, en colaboración con la Delegación de Gobierno de Murcia y con el apoyo de las Universidades Politécnica y Complutense de Madrid para el análisis de riesgo por encargo del Instituto Geográfico Nacional. Fue homologado por la Comisión Nacional de Protección Civil el 19 de julio de 2006.

Tanto el Plan Estatal como el de Comunidad Autónoma, han sido puestos a prueba tras la ocurrencia de los terremotos, y han sido la guía de las actuaciones para los intervinientes en las labores de protección civil.

\subsection{Sistemas de información sísmica}

Tanto el Plan Estatal como el de Comunidad Autónoma desarrollan un sistema de información sísmica con la finalidad de minimizar al máximo el tiempo de transmisión de la información sísmica para agilizar las actuaciones necesarias y paliar los posibles daños materiales o humanos que pueda ocasionar el suceso.

Los sistemas de información sísmica de ambos planes parten de la recepción de la información de los eventos sísmicos. Esta información es enviada por el Instituto Geográfico Nacional (IGN), que es el órgano competente para la planificación y gestión de sistemas de detección y comunicación de movimientos sísmicos ocurridos en territorio nacional y áreas adyacentes, así como para la realización de trabajos y estudios sobre sismicidad y la coordinación de la normativa sismorresistente. Una vez la DGPCE y el 112 de la Comunidad Autónoma afectada reciban la información sísmica, estas organizaciones difunden dicha información de acuerdo a lo establecido en sus procedimientos.

\section{Intervención}

En una emergencia por terremoto, la rapidez de actuación para el auxilio a la población es básica desde los primeros momentos, sin poder esperar a obtener datos de mayor detalle que permitan determinar la fase o la situación sísmica creada. Este apartado describe las acciones generales que los órganos de dirección y coordinación y demás intervinientes establecidos en los planes de emergencia debieron emprender para responder con eficacia ante las necesidades creadas por los efectos de los terremotos. 


\subsection{Primer Terremoto}

Siguiendo los procedimientos establecidos el 11/05/2011 a las 17:35 la Sala de Coordinación Operativa (SACOP) de la Dirección General de Protección Civil y Emergencias (DGPCE) recibió las comunicaciones correspondientes al primer terremoto con los siguientes parámetros:

Sismo ocurrido a las 17:05 horas del día 11/05/2011 en NE LORCA. MU (Murcia). Magnitud 4,4 mbLg. Longitud: -1,67 O - Latitud: 36,69 N (Evento 1060256)

Tal como está establecido en los protocolos de comunicación, el SACOP comunicó la ocurrencia de este evento a:

- Los cargos directivos de la DGPCE mediante mensaje de SMS

- Los gabinetes de información de la Delegación de Gobierno en Murcia.

- 112 de la Región de Murcia.

- Las Comunidades Autónomas colindantes.

Estos avisos son redundantes ya que el IGN en sus protocolos de transmisión de información distribuye la información a estas instituciones.

Dada la magnitud del terremoto, desde el SACOP, se recabó información sobre los efectos tanto al 112 como a la Delegación de Gobierno, a través de ellas, se conoció que este terremoto fue sentido ampliamente en la región de Murcia, Albacete y Almería, y que la Comunidad Autónoma de Murcia había activado el Plan SISMIMUR en situación 1, a las 17:40h, al considerarse que la protección de las personas y sus bienes podría quedar asegurada mediante el empleo de los medios y recursos del municipio afectado y de la Comunidad Autónoma.

A raiz de este terremoto, diferentes medios de comunicación social se trasladaron a la localidad para emitir en directo, con la consiguiente aportación de información en tiempo real del segundo terremoto, lo que permitió al SACOP conocer y evaluar la situación de forma continua.

\subsection{Segundo Terremoto}

A las 18:50, el SACOP recibió por los mismos medios, pero con procedimientos de urgencia (cálculo automático, con envío manual para Protección Civil) el aviso de un segundo terremoto con los parámetros:

Sismo ocurrido a las 18:47 horas del día 11/05/2011 en NE LORCA (Murcia). Magnitud 5,1 mbLg, intensidad VII. Longitud: -1,67 O - Latitud: 37,7 N (Evento 1060340)

Esta información, que se distribuyó de la misma manera que la del primer sismo, dio lugar (dada la magnitud) a muchas más reacciones:

- En la DGPCE, siguiendo los protocolos establecidos, se simularon los daños del terremoto con el programa SES 2002 según varias hipótesis, de lo que se dedujo que el terremoto podía ser de los más graves ocurridos en España en los últimos años. 


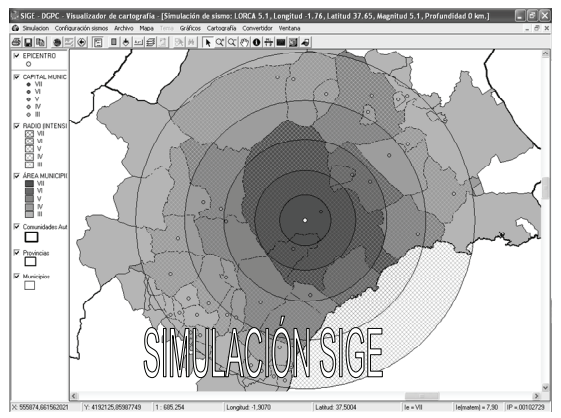
Simulación Terremoto: LORCA 5.1, Longitud -1.76, Latitud 37.65, Magnitud 5.1, Profundidad $0 \mathrm{~km}$.
INFORME SiSMICO DE INTENSIDADES V,Vl,VII
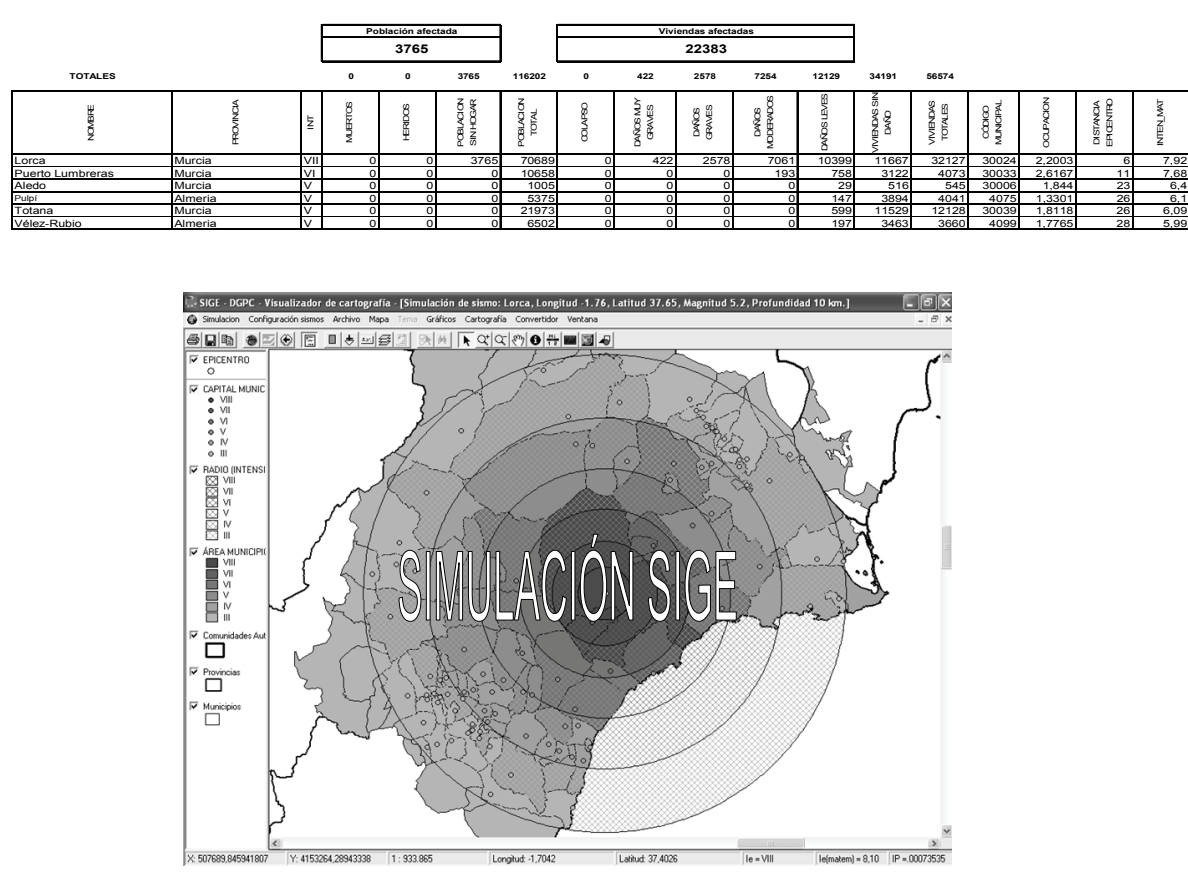

Simulación Terremoto: Lorca, Longitud -1.76, Latitud 37.65 , Magnitud 5.2, Profundidad $10 \mathrm{~km}$.

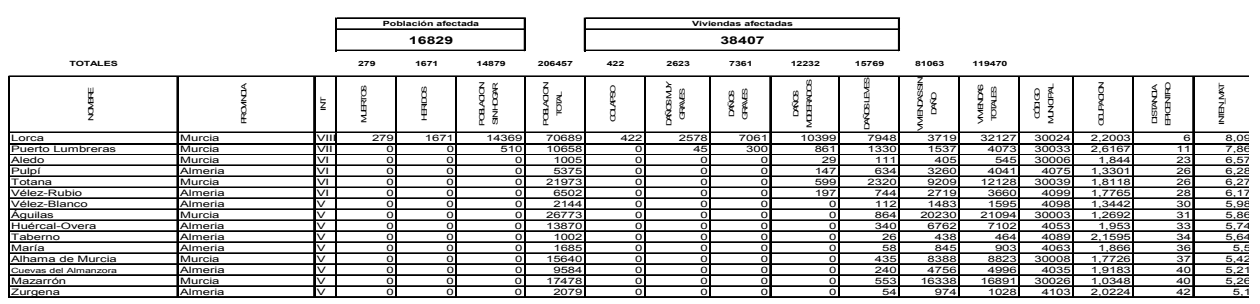

Fig. 3. Resultado de las simulaciones (SES 2002) 
- El análisis objetivo de la información por parte de la Administración del Estado, aceleró la toma de decisiones y la movilización en un tiempo record, entre otros, de la Unidad Militar de Emergencias, de medios y recursos de la Empresa TRAGSA, así como las activaciones de los convenios de la DGPCE con Cruz Roja Española y la empresa CARREFOUR para garantizar alojamiento y manutención a las personas que se habían quedado sin hogar.

En la Comunidad Autónoma se activó el Plan SISMIMUR en Situación 2, a las 19.20 (tras el segundo terremoto), lo que supone el concurso de medios, recursos o servicios extraordinarios de titularidad estatal no asignados al Plan SISMIMUR. La dirección pasó a ejercerse en un Comité de Dirección constituido por el responsable del órgano competente de la Comunidad Autónoma (el Consejero de Justicia y Seguridad Ciudadana) y un representante del Ministerio del Interior (en este caso, el Delegado del Gobierno en la Comunidad Autónoma de la Región de Murcia) en apoyo del primero. De forma automática, y para dar respuesta a las tareas de apoyo que la Administración Estatal había de prestar a la Administración Autonómica derivadas de la declaración del Nivel 2, se activó el Plan Estatal de Protección Civil ante el Riesgo Sísmico.

A las 21.30 horas, en la sede de la Dirección General de Protección Civil y Emergencias (Ministerio del Interior), se constituyó el Comité Estatal de Coordinación (CECO) bajo la presidencia del Subsecretario del Ministerio del Interior. Asistieron representantes de instituciones y organismos que define el Plan Estatal y disponen de medios útiles en la atención de la emergencia (DG Policía y Guardia Civil, DG Instituto Geográfico Nacional, DG Política de Defensa, DG Departamento de Infraestructura y Seguimiento para Situaciones de Crisis, DG Tráfico, DG Protección Civil y Emergencias, TRAGSA y Cruz Roja).

Este Comité, en coordinación y comunicación permanente con la Delegación del Gobierno en Murcia -que llevó a cabo las tareas de gestión de información, análisis permanente de la situación y la detección de necesidades, se encargó de coordinar las medidas a adoptar para la aportación y movilización de medios y recursos extraordinarios necesarios para reforzar y apoyar a los establecidos en el Plan SISMIMUR, promovió la activación de un Hospital Miliar de Campaña de la BRISAN (Brigada de Sanidad del Ejército de Tierra español), perteneciente a DIGENPOL, la activación del Convenio de Albergue y Asistencia Psicosocial en Cruz Roja y la movilización de una Unidad Móvil con estación sísmica del IGN.

El Puesto de Mando Avanzado se instaló en Lorca, en el recinto del "Huerto de la Rueda", y a él, desde un primer momento, se incorporaron los representantes y responsables de las diferentes administraciones. 
Tabla. 1. Resumen de las consecuencias.

\begin{tabular}{|c|c|}
\hline Muertos & 9 \\
\hline Heridos & 324 \\
\hline $1^{\mathrm{a}}$ noche fuera de casa & 60000 \\
\hline Campamentos iniciales & $\begin{array}{l}\text { I.E.S. Ibáñez Martín, Huerto de la Rueda y la } \\
\text { Viña. }\end{array}$ \\
\hline Campamento definitivo & La Torrecilla \\
\hline Raciones repartidas & 600 (12 de mayo) - 1420 (17 de mayo) \\
\hline $\begin{array}{c}\text { Inmuebles dañados con distinto grado de } \\
\text { afectación }\end{array}$ & $80 \%$ \\
\hline $\begin{array}{l}\text { Edificios evaluados según estimación rápida } \\
\text { habitabilidad }\end{array}$ & 7862 \\
\hline Establecimientos mercantiles afectados & 966 \\
\hline Establecimientos industriales & 94 \\
\hline Servicios con daños globales & 555 \\
\hline Servicios públicos afectados & $\begin{array}{c}\text { Educación, servicios sociales y servicios sanita- } \\
\text { rios }\end{array}$ \\
\hline Centros educativos con daños & 17 ( 5 con daños estructurales y 2 demolidos) \\
\hline Centros sanitarios dañados & $\begin{array}{c}2 \text { centros de salud ( } 1 \text { demolido) y un hospital } \\
\text { con actividad interrumpida durante los primeros } \\
\text { días. }\end{array}$ \\
\hline Infraestructuras & $\begin{array}{l}\text { A-7 (grietas en viaducto), RM-701 (pk. 0,6-2,7) } \\
\text { (desprendimientos), infraestructuras ferrovia- } \\
\text { rias, estación Lorca - Sutullena con daños } \\
\text { estructurales muy graves con colapso parcial de } \\
\text { planta superior. }\end{array}$ \\
\hline Servicios esenciales & $\begin{array}{l}\text { Interrumpidos con carácter preventivo gas y } \\
\text { electricidad. Saturación en telefonía móvil. }\end{array}$ \\
\hline Patrimonio cultural & $\begin{array}{l}\text { Rehabilitación o reconstrucción de } 60 \text { edificios } \\
\text { valorado en más de } 40 \text { millones de euros. }\end{array}$ \\
\hline
\end{tabular}



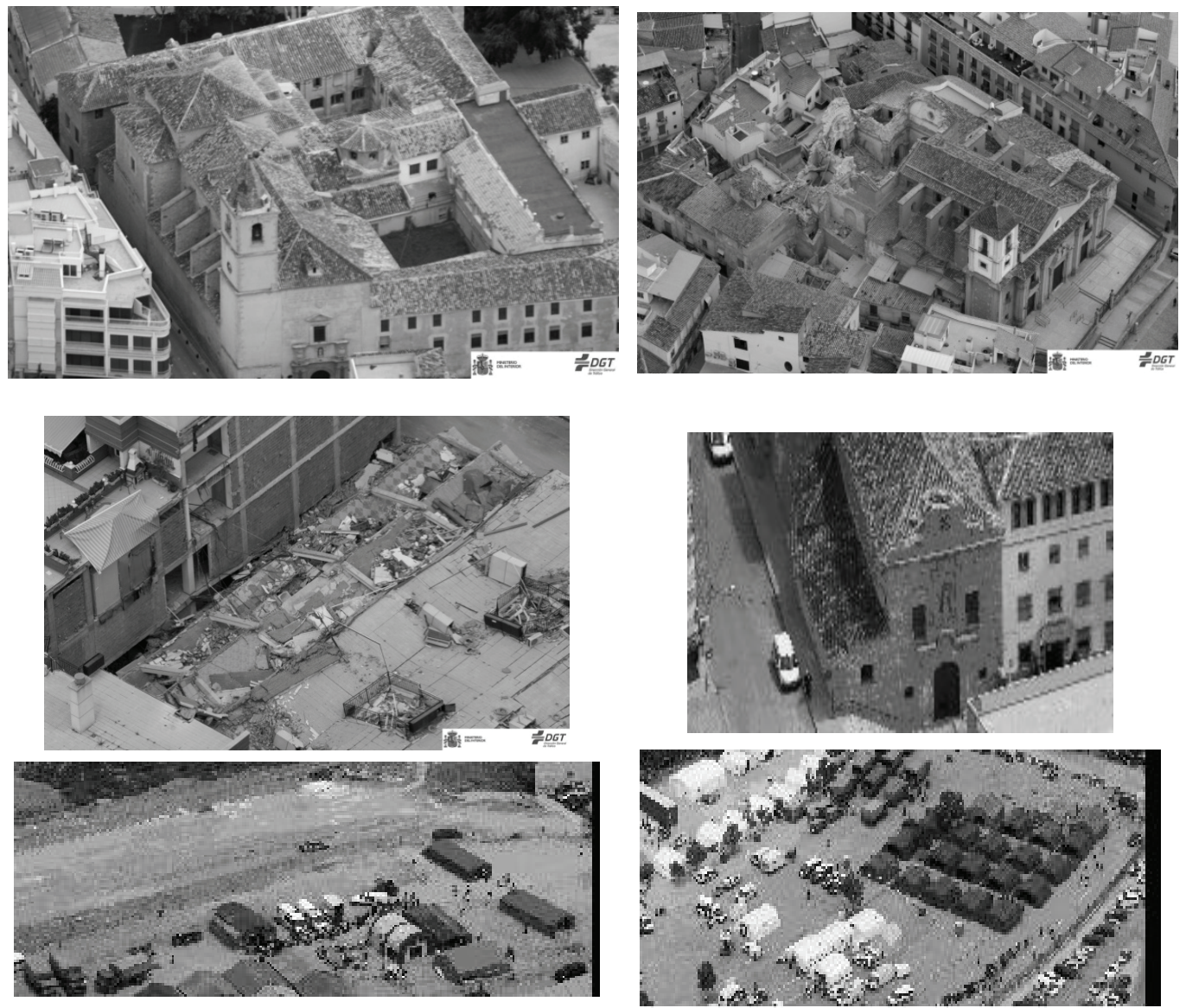

Fig. 4. Fotografías captadas por el helicóptero de tráfico en su viaje de inspección.

Desde la DGPCE, también se activó el programa SAFER de la Unión Europea, para la obtención de imágenes de satélite en emergencias creado dentro de la órbita de GMES. Por carencia de satélites que pudieran tomar imágenes con precisión suficiente en poco tiempo los primeros resultados de la interpretación de imágenes capturadas no llegaron hasta el lunes 18 de mayo, por lo tanto la evaluación de daños en edificios realizada por los técnicos en campo, resultó mucho más efectiva.

Dentro de este programa se realizaron unas pruebas de toma de imágenes desde un avión no tripulado que resultaron, dada la precisión y calidad de la imagen, de mucho mayor interés, con el inconveniente de tener que compartir espacio aéreo con los helicópteros de rescate.

Con el fin de obtener la máxima información posible se solicitaron imágenes de la empresa DEIMOS y posteriormente se obtuvieron imágenes Radar procesadas 
por la Universidad Politécnica de Barcelona tratando de evaluar el proceso de deformaciones
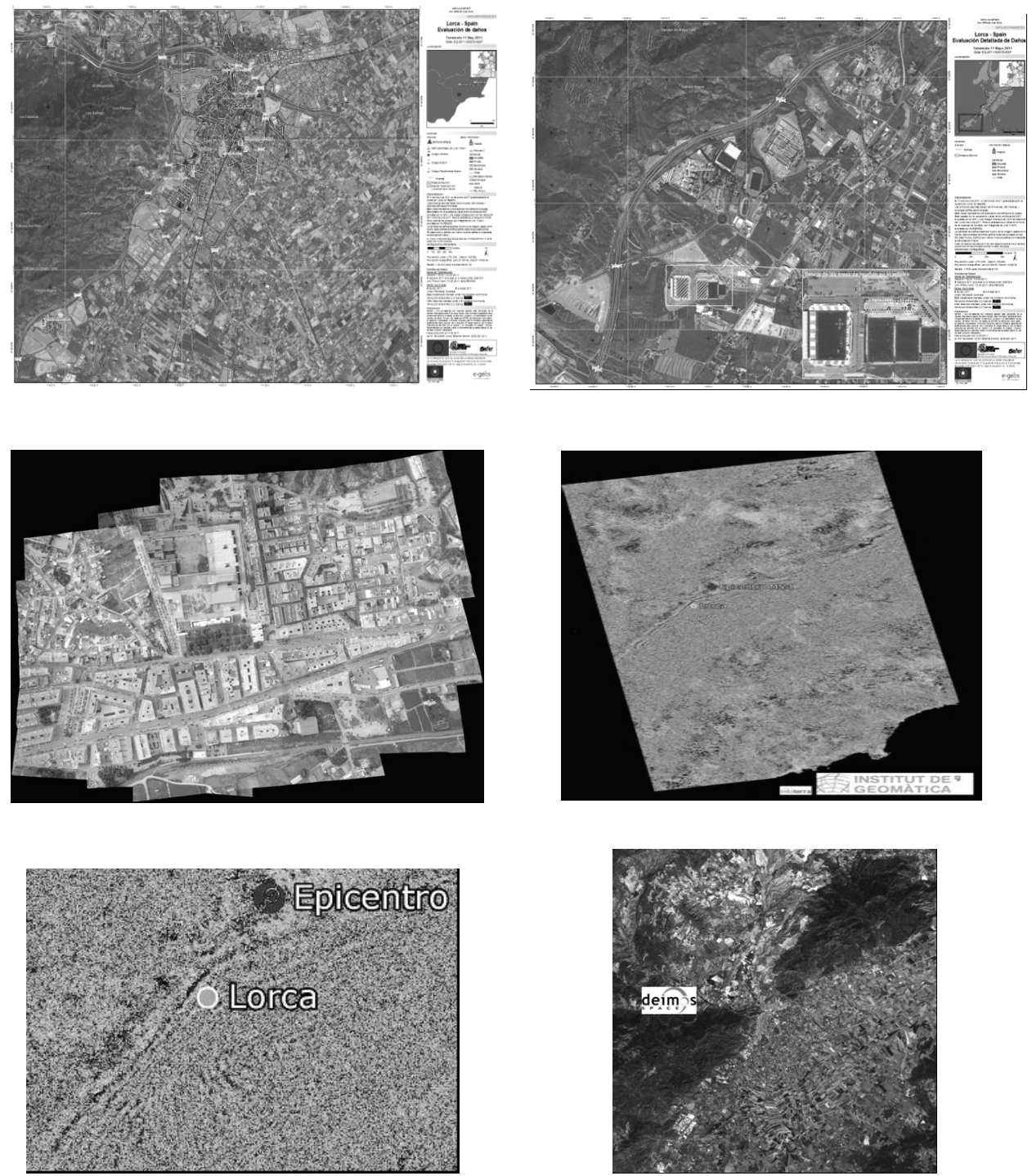

Fig. 5. Selección de productos de teledetección obtenidos por el programa SAFER y otras instituciones. 
Tal y como contempla el Plan SISMIMUR, las tareas de los medios, recursos y servicios extraordinarios estatales que participaron en el operativo de emergencia, lo hicieron como apoyo a los medios, recursos y servicios "ordinarios" contemplados en el mencionado Plan, orientándose básicamente a:

- Durante las primeras horas:

- Labores de búsqueda y rescate: los servicios de emergencia del Plan SISMIMUR se vieron reforzados por unidades especiales desplazadas a la zona, pertenecientes a las Fuerzas y Cuerpos de Seguridad del Estado y a la Unidad Militar de Emergencias, superando con creces los 1.000 efectivos. Hay que destacar que a diferencia de lo que se pudiera pensar en un primer momento, el número de personas que tuvieron que ser rescatadas fue muy limitado y en ningún caso hubo personas sepultadas bajo los escombros de los edificios ya que la existencia de un primer terremoto (precursor) amplia y severamente sentido, hizo que la mayor parte de la gente atemorizada abandonase sus hogares, encontrándose a la intemperie cuando se registró el segundo. Del mismo modo, un importante dispositivo de los diferentes servicios de emergencia de la Región se había desplazado a Lorca como consecuencia del primero y se encontraban inspeccionando la zona cuando se produjo el sismo principal con lo que su actuación fue inmediata, salvaguardando con ello un importante número de vidas.

- Atención de heridos y traslado en su caso a diferentes centros hospitalarios: se instaló un hospital de campaña por parte del Escalón Médico Avanzado del Ejercito con la correspondiente dotación de personal, que además de la atención de emergencia a heridos durante la fase de emergencia, se encargó de cubrir parte de las carencias sanitarias presentes en la zona derivadas de la existencia de infraestructuras e inmuebles sanitarios dañados como consecuencia de los movimientos sísmicos.

- En las horas siguientes, del elevado número de viviendas afectadas se derivaron tres tipos de actuaciones fundamentales:

- Albergue y avituallamiento de personas sin hogar (superior a una semana).

- Atención psicosocial a víctimas.

- Estimación rápida de daños en inmuebles e infraestructura (una semana) $\mathrm{y}$, en su caso, actuaciones de emergencia en los mismos (apeos, apuntalamientos, saneamiento de cornisas, antepechos, etc.).

- La estimación rápida de la habitabilidad se llevó a cabo por los técnicos del Ayuntamiento de Lorca y de la Comunidad Autónoma de la Región de Murcia, reforzados por técnicos voluntarios hasta un total de 200, desplazados desde todos los puntos de la geografía regional e incluso nacional. 
La ciudad se dividió en un total de 29 secciones, en las que trabajaron equipos de al menos dos técnicos apoyados por bomberos o especialistas de la Unidad Militar de Emergencia, capataces, etc., que bajo la instrucción de los técnicos se encargaron de acometer en los casos en los que así se consideró, las actuaciones de emergencia (apuntalamiento, apeo, etc.) necesarias para asegurar, en la medida de lo posible la estabilidad del inmueble. Se constituyó además un "Equipo 0 " formado por técnicos expertos en estructuras que se encargaron de revisar más a fondo y con mayor criterio los inmuebles con patologías más severas.

Para la estimación rápida de la habitabilidad se utilizó un código de colores con criterios establecidos "ad hoc" ante la falta de protocolos previos que seguía parámetros de seguridad que se pueden consultar en la tabla de la tabla 2 , junto con los resultados.

La falta de formación específica en "patologías sísmicas" y de entrenamiento y formación previa por parte de algunos de los técnicos de voluntarios, así como la ya indicada ausencia de protocolos previos, hizo que en ocasiones existiera cierta confusión derivada de la disparidad de criterios a la hora de evaluar, lo que en algunos casos, sembró la desconfianza convirtiéndose en cierta alarma social entre los moradores de las viviendas. Si bien es verdad, que el altruismo y la voluntariedad de la mayoría favoreció que en aproximadamente 72 horas se hubiera efectuado una primera estimación de la habitabilidad de los más de 7800 inmuebles que conforman el casco urbano de Lorca.

Tabla. 2. Resultado de la estimación rápida de la habitabilidad.

\begin{tabular}{|l|c|}
\hline \multicolumn{2}{|c|}{ Estimación Rápida Habitabilidad } \\
\hline Demolidas & $4,88 \%$ \\
\hline $\begin{array}{l}\text { Rojo, no habitables con daño } \\
\text { estructural severo }\end{array}$ & $8,27 \%$ \\
\hline $\begin{array}{l}\text { Amarillo, daño estructural } \\
\text { leve/moderado, necesitan } \\
\text { medidas de reparación o } \\
\text { rehabilitación }\end{array}$ & $19,26 \%$ \\
\hline Verde, daño no estructural & $67,59 \%$ \\
\hline
\end{tabular}

Además los equipos de expertos del Instituto Geográfico Nacional, y del Instituto Geológico y Minero de España, monitorizaron la zona y elaboraron informes sísmicos y tectónicos. Por otra parte la Dirección General de Bellas Artes y Bienes Culturales del Ministerio de Cultura que se encargó de llevar a cabo la estimación 


\title{
inicial del daño en el Patrimonio Cultura en apoyo de los técnicos del órgano com- petente de la Comunidad Autónoma.
}

\author{
CRONONOLOGIA RESUMIDA DEL TERREMOTO DE LORCA (MURCIA)
} (11 de mayo de 2011)

$17: 35 \mathrm{~h}$

\section{DÍA 11 DE MAYO DE 2011}

El SACOP recibe mediante fax la siguiente información: Sismo ocurrido a las 17:05h en NE LORCA, Magnitud 4,4 mbLg. Longitud: -1,67 O, Latitud: $36,69 \mathrm{~N}$ Este terremoto ha sido sentido ampliamente en la región de Murcia Albacete y Almería.

$17: 40 \mathrm{~h}$

Activación del Plan Especial de Protección Civil ante el Riesgo Sísmico en la Región de Murcia (SISMIMUR), Nivel 1. Un equipo de TVE acude a Lorca para grabar en directo la situación generada por el terremoto ocurrido.

18:50

EI SACOP recibe mediante fax la siguiente información:

Sismo ocurrido a las 18:47h en NE LORCA, Magnitud $5.1 \mathrm{mblg}$, Intensidad VII. Longitud: $-1,670$, Latitud: $37,7 \mathrm{~N}$. Superficial.

La Delegación del Gobierno en Murcia informa telefónicamente de: Se va a solicitar a la UME por petición de la Comunidad Autónoma. Podría haber personas atrapadas. Constituido CECOPI. Nivel 2 del SISMIMUR.

19:16h

El centro de Lorca esta lleno de cascotes, es una zona muy poblada. Se realizan dos simulaciones del terremoto para estimar los daños ocasionados con el SES 2002.

19:30h

Aportaciones de la REMER (Red de EMergencia de Radioaficionados)

19:34h

Llama el MIC solicitando información sobre el terremoto y ofrece ayuda en caso de ser necesario.

19:40h

Desde el SACOP, se informa por email a DIGENPOL y UME de la ocurrencia

de los sismo y de la inmediata solicitud de la UME.

20:30h

La UME comunica que hace 5 minutos había salido de Bétera el primer elemento de intervención y reconocimiento.

20:33h

La Delegación del Gobierno en Murcia confirma que hay 8 fallecidos, pide información de medios de la UME enviados y hora estimada de llegada.

21:15h

Presidido por el Subsecretario de Interior se constituye el Comité Estatal de Coordinación (CECO) en la DGPCE. Actuaciones:

- Movilización de medios de la Policía y de la Guardia Civil.

Movilización de medios de la DG de Tráfico.

Activación por DIGENPOL de un Hospital Militar de Campaña de Ia BRISAN.

- Activación del Convenio de Albergue y Asistencia psicosocial en Cruz Roja.

22: $10 \mathrm{~h}$

Movilización de la Unidad Móvil con Estación Sísmica.

Cruz Roja Española nos comunica que todos los equipos de respuesta inmediata están prealertados y a petición de la CA Murcia activado equipo para albergar desplazados.

Activado el convenio con Carrefour para suministrar comida y agua. La CA Activado el convenio con Carre
prevé unos 20.000 desplazados.

22:30h

Se informa al Director General de Emergencias de la Región de Murcia del Se informa al Director General de Emergencias de la Región de Murcia de Cataluña, llles Baleares y Madrid, asi como de los Departamentos de PC de Cataluña, Iles Baleares y Madrid, asi como

Francia,

La Delegación del Gobierno en Murcia informa que el hospital comarcal de Lorca ha habilitado dos plantas para acoger mas heridos, se han evacuado tres residencias de ancianos, múltiples edificios con grietas, caídas de tejas y cornisas, daños en el castillo, una iglesia y el viaducto de la A-7.

01:05h DÍA 12 DE MAYO DE 2011

El IGN ha enviado la Unidad Móvil con Estación Sísmica con transmisión satélite. Están alertados los equipos de apoyo psicosocial y dos equipos mas de albergue provisional.

01:44h

10.000 personas albergadas, UME y Cruz Roja interviniendo, habilitadas zonas albergue y reparto alimentos.

09:04h

El IGN publica el primer informe, de carácter diario, sobre el terremoto.

Alertados 3 helicópteros de la UME, finalizadas las labores de búsqueda y

rescate de personas.

13:00h

Segunda reunión de CECO presidido por la directora General de protección Civil para valorar la situación.

protec

Se confirma el fallecimiento de una de las tres personas en estado grave. 14:21 h

\section{Normalización}

La CA ha puesto en marcha un dispositivo formado por arquitectos, aparejadores y técnicos de la Administración Regional para valorar los daños en edificios y viviendas.

20:41h

Hay 200 profesionales trabajando en la evaluación de viviendas. Se ha dividido la localidad en 26 áreas y se han evaluado 19 , de los 542 edificios revisados hasta el momento, $40 \%$ verde libres para entrar $17 \%$ rojo no habitables hasta rehabilitación, $39 \%$ amarillo habitables con precauciones, sin daños estructurales, pueden entrar a coger enseres. díA 13 DE MAYO DE 2011

Real Decreto-Ley $6 / 2011$, de 13 de mayo, por el que adoptan medidas urgentes para reparar los daños por los movimientos sísmicos acaecidos el 11 de mayo de 2011 en Lorca (Murcia). (BOE núm. 115 de 14 de mayo) 11 de mas

08:53h
Se constituye el PMA (Puesto de Mando Avanzado) en parque Huerto de la Rueda.

13:39

Cruz Roja informa que se han repartido 2240 kits de comida, desayunos y se ha facilitad
$13: 59 \mathrm{~h}$

13:59h

El servicio de urgencias del Hospital Rafael Méndez ya esta operativo. Progresivamente se irán reabriendo los demás servicios, ya que no ha sufrido daños estructurales.

23:13h

Heridos: 324 (de ellos 3 graves).

Los 3 heridos muy graves ingresados en el Hospital Arrixaca (Murcia). Albergue

A las $23 \mathrm{~h} 00$ del día 13/05 400 personas se encuentran en la Guardería Virgen del Carmen donde pasarán la noche.

Edificaciones destruidas

DÍA 15 DE MAYO DE 2011

Aceptada la solicitud para ampliar en 1.300 plazas de reserva el alojamiento y crear un nuevo emplazamiento en las cercanías del campo de fútbol, en la zona de Oñate. Se va a realizar el desmontaje progresivo de los 3 campamentos actuales en función del desalojo de sus ocupantes.

DíA 16 DE MAYO DE 2011

Restablecimiento del servicio de gas en aquellas viviendas que no se han visto afectadas.

DíA 17 DE MAYO DE 2011

CONVENIO SUSCRITO el día 17 de mayo entre MF, CCAA de la REGIÓN DE MURCIA y AYUNTAMIENTO de LORCA, para gestión de las medida establecidas en el artículo 3.1c) del RDL 6/2011: reparación, rehabilitación y reconstrucción de viviendas. (Resolución BOE 17/06/2011)

El campamento de "La Torrecilla esta ya montado a falta de 400 literas, tendrá una capacidad de 1400 plazas. Ya se ha producido la trasferencia en la gestión del campamento a la CAR de Murcia, a la DG de Seguridad Ciudadana y Emergencias. A las 09:30 se desalojaba el Recinto Ferial y a las 10h se preveía la llegada de los primeros damnificados. DÍA 20 DE MAYO DE 2011

Solicitud de desactivación del Hospital de Campaña y de la Unidad Médica Militar.

\section{DÍA 25 DE MAYO DE 2011}

Solicitud de desactivación parcial de la UME.

Se publica el informe realizado por el IGME, sobre el terremoto. DÍA 25 DE JULIO DE 2011

Informe conjunto IGN-IGME-UPM COn el resumen de los informes Informes del IGN y el efectuado por el IGM/UPM que se envía al Gobierno. diarios del IGN y el efectuado por el IGM/UPM que se

Continúan 5 efectivos y 2 vehículos de la UME en el campamento de "La Torrecilla", que se espera cerrar el 11 de noviembre. DÍA 28 DE OCTUBRE DE 2011

Resolución de 28 de octubre de 2011 , del Comisionado del Gobierno para las actuaciones derivadas del terremoto de Lorca, por la que se publica e Acuerdo del Consejo de Ministros de 28 de octubre de 2011, por el que se adoptan medidas complementarias a las contenidas en los Reales Decretos-leyes 6/2011, de 13 de mayo, y 17/2011, de 28 de octubre, para reparar los daños causados por los movimientos sísmicos acaecidos el 11 de mayo de 2011 en Lorca (Murcia) ((BOE núm. 263 de 1 de noviembre). DíA 29 DE OCTUBRE DE 2011

Se solicita la desactivación de la UME en Lorca. DíA 31 DE OCTUBRE DE 2011

Real Decreto-Ley 17/2011, de 31 de octubre, por el que se establecen medidas complementarias para paliar los daños producidos por los movimientos sísmicos acaecidos en Lorca el 11 de mayo de 2011 se modifica el Real Decreto-ley $6 / 2011$, de 13 de mayo, y se adoptan medidas fiscales $y$ laborales respecto de la isla de El Hierro (Murcia). (BOE núm. 263 de 1 de noviembre)

DÍA 11 DE NOVIEMBRE DE 2011

Se cierra el campamento de "La Torrecilla"

La Comunidad Autónoma desconvoca el CECOPI 
En la fase de normalización se llevan a cabo todas las medidas y actuaciones encaminadas a restablecer los daños ocasionados por el terremoto con el fin de que la población vuelva a la situación que había antes de que ocurrieran los terremotos. (reconstrucción/ reparación de daños en los edificios y medidas económicas).

Con fecha 14 de mayo de 2011, tan solo 3 días después de que se registraran los terremotos, se publicó en el BOE el Real Decreto-ley 6/2011, de 13 de mayo, por el que se adoptan medidas urgentes para reparar los daños causados por los movimientos sísmicos acaecidos el 11 de mayo de 2011 en Lorca, Murcia (RDL).

El 18 de mayo de 2011, la Comunidad Autónoma de la Región de Murcia publica el Decreto 68/2011, de 16 de mayo, por el que se regulan las ayudas para la reparación y reconstrucción de las viviendas afectadas por los movimientos sísmicos, acaecidos el 11 de mayo de 2011, en el municipio de Lorca, complementario al RDL 6/2011 y que establecía los procedimientos para la concesión y pago de las ayudas para la rehabilitación, reparación o reconstrucción en su caso de las viviendas siniestradas en el término municipal de Lorca. Estableciendo plazo de un mes para la presentación de solicitudes a partir de la publicación del Decreto en el BORM, registrándose un total de 13028 solicitudes. En este caso, las ayudas consistían en:

- Ayudas para reparación y rehabilitación de vivienda habitual, cuyo importe máximo sería el del valor de los daños producidos hasta un máximo de $24000 €$. En este caso se presentaron un total de 11.817 solicitudes, con un presupuesto total estimado en $41.443 .645,47 €$.

- Ayudas para reconstrucción de viviendas: cuyo importe máximo sería el valor de los daños producidos hasta un máximo equivalente al $80 \%$ del coste de una vivienda de Protección Oficial en Lorca (106 000€). Hay que tener en cuenta que se demolieron un total de 264 inmuebles, afectando a un total de 1.264 viviendas de ellas 915 propietarios solicitaron ayuda, con un presupuesto total estimado en 58.194.000,00 €

La financiación de estas ayudas corre a cargo de la CARM al 50\% y del Ministerio de Fomento el resto.

Respecto a las estimaciones, en ambos casos, al ser complementarias, se han descontado las indemnizaciones que por ésta misma causa ha abonado el Consorcio de Compensación de Seguros y que se elevan a 382,3 millones de euros sobre un total de 31.000 indemnizaciones

El 25 de mayo de 2011, la Comunidad Autónoma de la Región de Murcia publicó, el Decreto 92/2011, de 20 de mayo, por el que se regulan las ayudas para el alquiler de viviendas y reposición de enseres de las viviendas afectadas por los movimientos sísmicos, acaecidos el 11 de mayo de 2011, en el municipio de Lorca, igualmente complementario del RDL6/2011 y que establece los procedimientos para la concesión y pago de este tipo de ayudas. Fijando un plazo de seis meses para la presentación de solicitudes a partir de la publicación del Decreto en el BORM. 
- Ayudas para Alquiler de viviendas: durante un periodo que oscila desde los 12 meses (reparación) a los 24 meses (reconstrucción), con posibilidades de prórroga. Cuantía máxima de $74 € / \mathrm{m}^{2} /$ año hasta un máximo de $6.671,7 € / a n ̃ o$ $(555,97 € / \mathrm{mes})$. En este caso se presentaron un total 1559 solicitudes cuya estimación se eleva a $11.783 .950,25 €$

- Enseres de primera necesidad: cuantía máxima $2580 €$. Con un total de 588 solicitudes con una estimación máxima de 1.470.000,00€

Financiación: Ministerio del Interior 50\% y 50\% CARM.

Por otra parte, el Consorcio de Compensación de Seguros, entidad pública dependiente del $\mathrm{M}^{\circ}$ de Economía y Competitividad, empezó a trabajar desde el minuto 0 , desplazando más de 200 peritos a la zona que, en un tiempo record, se encargaron de evaluar el daño en todos aquellos inmuebles que en el momento del sismo tenían contratada póliza de seguro y que así lo habían solicitado. Diez meses después del terremoto, el Consorcio había tramitado más de 31.000 expedientes, que afectaban a viviendas, comercios, oficinas, industrias, vehículos y daños personales, superando el $99 \%$ del total de solicitudes, abonando más de 382 millones de euros en concepto de indemnización.

El 20 de mayo, quedó constituida la Oficina Unificada de Atención a los Damnificados, con dos sedes ubicadas en el municipio de Lorca, una en el Centro de Desarrollo Local y la otra en el Centro Cultural. Estaba atendida por funcionarios de las diferentes Administraciones Públicas (Local, Autonómica y Estatal). En ella se informaba y se recepcionaban las solicitudes de ayudas o de adopción de todas aquellas medidas contempladas en el RDL 6/2011 y la normativa complementaria. Las oficinas estaban atendidas por un total de 80 funcionarios que trabajaban en turnos de mañana y tarde, a razón de unas 22 personas por turno y oficina: unas 44 personas por oficina y día. En cada oficina se instalaron veinte puestos informáticos, atendidos por otros tantos tramitadores. El resto de funcionarios realizaba tareas de información a los ciudadanos y tramitación del sistema de cita previa en cada turno de cada oficina.

El martes 31 de mayo, equipos de técnicos de la comunidad autónoma inician las tareas de tasación pericial de daños en viviendas necesarias para la tramitación, gestión y resolución de ayudas establecidas en el artículo 3 del RDL 6/2011, de 13 de mayo. Se realizan unas 200 valoraciones diarias por un total de 30 técnicos.

Se estableció un sistema electrónico para la tramitación de los expedientes, con el desarrollo de las correspondientes aplicaciones informáticas, en la que además de las solicitudes, y de la documentación acreditativa aportada por el solicitante, se cruzaba la información procedente de bases de datos de diferentes organismos, necesarios para la tramitación (catastro, Consorcio de Compensación de Seguros, Agencia Estatal de Administración Tributaria, etc.).

Con fecha 31 de mayo, y como desarrollo al artículo 3.1.b) del Real DecretoLey 6/2011, se promulgó la Orden INT/1467/2011 que regulaba todo lo relativo a 
gastos de emergencia, que tenía como finalidad conceder una subvención del 100\% al Ayuntamiento de Lorca y que contemplaba todos aquellos gastos en los que había incurrido el citado Ayuntamiento por actuaciones encaminadas a garantizar la vida y seguridad de las personas, así como el funcionamiento de los servicios públicos básicos, incluyendo entre otros de forma explícita demoliciones de inmuebles, apuntalamientos, desescombras, etc. Estos gastos fueron financiados al $100 \%$ por el Ministerio del Interior en una cuantía próxima a los 20 millones de euros.

El 20 de mayo de 2011, con el objetivo de organizar, concentrar y gestionar todas las ayudas que llegaban de forma solidaria procedentes de fundaciones, empresas, entidades financieras o personas anónimas para los vecinos de Lorca, se constituyó la mesa de solidaridad.

En la sesión de 15 de junio se aprobaron las normas de funcionamiento de la "Mesa de Solidaridad" que fijaban como objetivo básico y primordial: La colaboración en la gestión de las ayudas y donaciones de cualquier tipo, que se reciban por cualquiera de los miembros, destinadas a paliar los efectos producidos por los terremotos de Lorca, como refuerzo y apoyo a la acción organizada e institucional de los poderes públicos.

Con fecha 1 de noviembre de 2011 se publicó en el Boletín Oficial del Estado el Real Decreto-Ley 17/2011, de 31 de octubre, por el que se establecen medidas complementarias para paliar los daños producidos por los movimientos sísmicos acaecidos en Lorca el 11 de mayo de 2011, se modifica el Real Decreto-Ley 6/2011, de 13 de mayo, y se adoptan medidas fiscales y laborales respecto de la isla de el Hierro. Junto a ello, se publicó el Acuerdo del Consejo de Ministros de 28 de octubre de 2011, por el que se adoptan medidas complementarias a las contenidas en los Reales Decretos-leyes 6/2011, de 13 de mayo, y 17/2011, de 28 de octubre, para reparar los daños causados por los movimientos sísmicos acaecidos el 11 de mayo de 2011 en Lorca (Murcia). Se recogen así un total de 37 medidas adicionales, tendentes a cubrir aquellas carencias y/o necesidades que no hubieran sido suficientemente recogidas en el RDL 6/2011, así como un amplio abanico de actuaciones y recomendaciones técnicas y jurídicas favorecedoras de las tareas de reconstrucción y reactivación de la ciudad, lo que conlleva una inversión sin precedentes acorde con la magnitud de los hechos.

Entre las nuevas medidas destacaban las recogidas en la disposición final primera del citado Real Decreto Ley y que hacían referencia a:

- Concesión de ayudas para cubrir los gastos en que incurriese el Ayuntamiento de Lorca derivados de las actuaciones imprescindibles e inaplazables que se acometiesen para garantizar la protección de los bienes del patrimonio cultural de la ciudad frente a fenómenos meteorológicos susceptibles de producir en dichos bienes daños que agravasen el deterioro que ya sufrían como consecuencia del terremoto del 11 de mayo de 2011. En este caso se presentaron un total de 
20 actuaciones por importe superior a los 2,5 millones de euros que han sido financiados al $100 \%$ por el $\mathrm{M}^{\mathrm{o}}$ del Interior.

- En el caso de reconstrucción de viviendas establecía que podrían beneficiarse de esta ayuda los propietarios de viviendas demolidas que no constituyesen su vivienda habitual siempre que al menos el $80 \%$ de las viviendas del edificio siniestrado sí constituyan el domicilio habitual de sus propietarios

- En el caso de comunidades de propietarios para los supuestos de reparación y/o rehabilitación se contemplaban ayudas cuyo importe sería equivalente al daño tasado siempre que no superase los $3000 €$ por vivienda o elemento privativo del edificio. La financiación se efectuaría al 50\% entre la Comunidad Autónoma y el $\mathrm{M}^{\mathrm{o}}$ de Fomento y que a una media de 4 viviendas o elemento privativo por edificio afectado susceptible de reparar, la cuantía estimada por esta causa superaría los 99 millones de euros.

- Se contemplan ayudas para reparación, rehabilitación y reconstrucción de locales o establecimientos mercantiles, industriales o de servicios, cuya cuantía no podría ascender de los 8000 euros, siendo requisito indispensable que en el momento del siniestro dispusieran de póliza de aseguramiento y menos de 50 empleados

A todo esto habría que añadir una amplía batería de medidas indirecta caso de las bonificaciones fiscales, medidas de dinamización económico y social. Si bien, el gran reto es la reconstrucción de la ciudad siguiendo estándares de confort y seguridad propios del siglo XXI, con la mentalidad de que si en un futuro se vuelve a registrar un sismo de estas características las consecuencias sean las mismas, solo así se podrá hablar de que las medidas adoptadas han surtido su efecto.

Tabla. 3. Estimación de costes económicos de la administración.

\begin{tabular}{|c|c|}
\hline \multicolumn{2}{|c|}{ RESUMEN DE LAS A YUDAS APROBADAS (a 20/7/2012) } \\
\hline$A Y U D A S$ & IMPORTES \\
\hline POR DAÑOS PERSONALES (fallecidos) & $\begin{array}{l}144.000,00 € \\
\text { (8 fallecidos con derecho a ayuda } \times 18.000 €)\end{array}$ \\
\hline $\begin{array}{l}\text { POR ALQUILERES DE VIVIENDAS } \\
\text { (aportación MIR } 50 \% \text { de los alquileres) }\end{array}$ & $\begin{array}{c}3.408 .792,75 € \\
(50 \% \text { de } 968 \text { ayudas concedidas por importe } \\
\text { totalde } 6.817 .585,50 €)\end{array}$ \\
\hline $\begin{array}{c}\text { POR REPARACIÓN/RECONSTRUCCIÓN } \\
\text { DE VIVIENDA } \\
\text { (aportación MFOMENTO } 50 \% \text { ) }\end{array}$ & $\begin{array}{c}14.104 .415,40 € \\
\text { (50\% de } 4.071 \text { ayudas concedidas por } \\
\text { importe to tal de } 28.208 .930,80 €)\end{array}$ \\
\hline $\begin{array}{c}\text { POR REPARACIÓN/RECONSTRUCCIÓN } \\
\text { DELOCALES } \\
\text { (aportación MIR } 50 \% \text { ) }\end{array}$ & $\begin{array}{c}356.328,35 € \\
(50 \% \text { de } 132 \text { ayudas concedidas por importe } \\
\text { total de } 712.656,70 €)\end{array}$ \\
\hline $\begin{array}{c}\text { GASTOS ACTUACIONES DE } \\
\text { EMERGENCIA YDEMOLICIÓN (pagos aI } \\
\text { AYUNTAMIENTO) }\end{array}$ & $20.944 .391,10 €$ \\
\hline $\begin{array}{c}\text { REQUERIMIENTOS EFECTUADOS POR } \\
\text { DELEGACIÓN DEL GOBIERNO Y DGPCYE }\end{array}$ & $212.241,00$ \\
\hline TOTAL & $39.170 .168,60 €$ \\
\hline
\end{tabular}

\section{Conclusiones}


Los planes y procedimientos del Sistema Nacional de Protección Civil han funcionado. Básicamente, la información a la población y la colaboración de la ciudadanía ha permitido poner en marcha y desarrollar todos los elementos de planificación previamente plasmados.

Los protocolos y procedimientos de comunicación de eventos sísmicos han funcionado razonablemente bien.

Se han desarrollado algún nuevo procedimiento de análisis de daños, usando imágenes aéreas georreferenciadas, pero no han dado todo los que se podía esperar de ellos. Los medios tradicionales de análisis in situ, mediante profesionales capacitados han producido información más rápida y de mejor calidad que la recogida por teledetección, a pesar de pequeñas inconsistencias producidas durante su desarrollo.

Con la experiencia acumulada por este terremoto resulta necesario establecer más pormenorizadamente los protocolos de análisis de daños, mediante la colaboración de todas las instituciones coparticipes, intentando posteriormente que los profesionales capacitados conozcan los procedimientos acordados.

\section{Referencias bibliográficas}

LEY 2/1985, de 21 de enero, sobre Protección Civil. BOE núm. 22, de 25 de enero de 1985.

REAL DECRETO 407/1992, de 24 de abril, por el que se aprueba la Norma Básica de Protección Civil. BOE núm. 105, de 1 de mayo de 1992.

RESOLUCIÓN de 5 de mayo de 1995, de la Secretaría de Estado de Interior, por la que se dispone la publicación del Acuerdo del Consejo de Ministros por el que se aprueba la Directriz Básica de Planificación de Protección Civil ante el Riesgo Sísmico. BOE de 25 de mayo de 1995.

RESOLUCIÓN de 17 de septiembre de 2004, de la Subsecretaría, por la que se ordena la publicación del acuerdo del Consejo de Ministros, de 16 de julio de 2004, por el que se modifica la Directriz Básica de Planificación de Protección Civil ante el Riesgo Sísmico, aprobada por el Acuerdo del Consejo de Ministros de 7 de abril de 1995. BOE de 2 de octubre de 2004.

DIRECCIÓN GENERAL DE PROTECCIÓN CIVIL. Comunidad Autónoma de la Región de Murcia, Consejería de Presidencia. Plan Especial de Protección Civil ante el Riesgo Sísmico en la Región de Murcia (SISMIMUR).2008.372.

RESOLUCIÓN de 29 de marzo de 2010, de la Subsecretaría, por la que se publica el Acuerdo de Consejo de Ministros de 26 de marzo de 2010, por el que se aprueba el Plan Estatal de Protección Civil ante el Riesgo Sísmico. (BOE núm. 86 de 9 de abril de 2010).

RESOLUCIÓN de 28 de octubre de 2011, del Comisionado del Gobierno para las actuaciones derivadas del terremoto de Lorca, por la que se publica el Acuerdo del Consejo de Ministros de 28 de octubre de 2011, por el que se adoptan medidas complementarias a las contenidas en los Reales Decretos-leyes 6/2011, de 13 
de mayo, y 17/2011, de 28 de octubre, para reparar los daños causados por los movimientos sísmicos acaecidos el 11 de mayo de 2011 en Lorca (Murcia).( Boletín Oficial del Estado: 1 de noviembre de 2011, Núm. 263).

REAL DECRETO 997/2002, de 27 de septiembre, por el que se aprueba la norma de construcción sismorresistente: parte general y edificación (NCSR-02). (BOE núm. 244, de 11 de octubre de 2002).

REAL DECRETO 637/2007, de 18 de mayo, por el que se aprueba la Norma de Construcción Sismorresistente: puentes (NCSP-07). (BOE núm. 132 de 2 de junio de 2007).

ORDEN INT/3376/2011, de 28 de noviembre, por la que se delegan determinadas competencias en los Delegados del Gobierno en la Comunidad Autónoma de la Región de Murcia y en Illes Balears y en los Subdelegados del Gobierno en Barcelona, Tarragona, Lleida, Girona, Castellón, Valencia, Alicante y Gipuzkoa, en materia de concesión de subvenciones. 